\title{
Public Finance Management: Challenges and Opportunities
}

\author{
By Liudmila Tkachenko*
}

\begin{abstract}
The paper reveals the essence of the system of public financial management (PFM), defines its key elements of PFM system and articulates goals and objectives. The author's definition of PFM is given. A comparative analysis of managerial financial cycles in the public and private sectors of the economy is carried out. The historical aspect of the PFM reforms is also analyzed, and various approaches to financial management (income and expenditure) in the public sector are studied. Factors influencing the effectiveness of the PFM reforms are revealed. The challenges faced by financial managers in implementing public finance reforms are analyzed, and the opportunities that can be used to achieve the objectives of the PFM system, some of which are simultaneously challenges (Blockchain and open government data $(O G D))$, are analyzed. (JEL H5, H50)
\end{abstract}

Keywords: Public Finance Management, Efficiency of PFM Reform, Key Elements of the PFM System, Blockchain in the Public Sector, Open Government Data.

\section{Introduction}

The public sector of the economy, as a rule, established itself as a leading choice in the economy of developed countries. The effective functioning of this sector depends on qualified management, to make management decisions with respect to such organizations.

It should be noted that the most modern management technologies in the field of finance developed and proved to be successful in practice for commercial organizations. Commercial organizations are aimed at profit and welfare of its shareholders. These goals are easily measurable and formalized in enough indicators showing the achievement of the organization's business objectives.

The entities of the public sector are significantly different from commercial organizations. The purpose of entity of public sector is to provide public goods, such as services in the field of law enforcement, health, education and others, rather than increasing shareholder wealth. The economic effect of such services is difficult to measure. The effect of the provision of those services cannot be measured by referring to the cost benefits, because the benefits of such services are impossible to calculate in monetary terms. For example, benefits from the provision of health services, is to increase the public health of the nation. The complexity in measuring of the effectiveness of public sector entities requires the

\footnotetext{
*Associate Professor, Department of Finance and Accounting, Institute of Economics and Management, National Research Tomsk State University, Russia.
} 
use of appropriate tools by management in the field of public finance management.

To date, there is no single approach to understanding what public financial management is. Clarity in the definition will allow to more clearly formulate the principles that will serve as the basis for building the structure and processes of financial management in the public sector to identify existing problems and the lack of resources. The main goal of building these processes is to improve the efficiency of public finance management, increase the transparency of the budget process, and increase the accountability of the subjects of their processes. In most cases, the achievement of these goals requires large-scale reforms in this area affecting related sectors of the economy (for example, the private sector) and the involvement of a large number of actors (for example, civil society) in this process.

At the present stage, governments of different countries in the implementation of PFM reforms face different challenges. So, the complexity and multiplicity of the process of managing public finances, in itself, is a challenge for those responsible for the results of this process.

Governments of various countries are under pressure to improve public sector performance and at the same time contain expenditure growth. While factors such as ageing populations and increasing health care and pension costs add to budgetary pressures, citizens are demanding that governments be made more accountable for what they achieve with taxpayers' money. (Curristine et al. 2007: 2)

In addition, the modern stage of public finance management is complicated by the presence of such phenomena as: the global economic crisis; globalization, exacerbating the effects of the crisis; terrorism; disease; public opinion, rapidly emerging in social networks; new technologies; uncertainty and other factors.

In modern conditions, public finances managers have to take into account a variety of factors and various risks in order to solve the tasks set by the society for effective financial management. To this end, public finance managers are forced to change approaches to management from traditional to new approaches.

New financial technologies, such as blocking, can be classified as new approaches to financial management in the public sector. This technology is known, to a greater extent, in connection with financial markets. However, such properties of this technology as the availability of data and the inability to hide the change in information (about changes become known to all participants in the chain) with haste can also be used in the management of public finances.

Undisputed challenge and the opportunity to improve all processes in financial management are open government data (OGD), the usefulness of which is their accessibility and the ability to use all participants in the budget process to solve various tasks. However, it must be remembered that these data should be presented within certain limits, so as not to create threats to state security. In addition, the use of these data imposes an additional responsibility on all users to maintain confidentiality.

The present study is devoted to the search for answers to the following questions: what is Public Financial Management (PFM); are there differences in 
financial management cycle in the public and private sectors of the economy; what are the key elements of the PFM system; which means an effective PFM system and its objectives; what approaches to reform implementation exist; what factors influence the effectiveness of PFM reforms; what are the challenges and opportunities for the PFM to achieve the goal.

\section{Literature Review}

This literature review consists of a review of existing publications by research theorists who have studied issues of reforming PFM, the key elements of such a complex process, which is the issue of PFM, issues of evaluating the effectiveness of PFM, and practitioners in public finance.

To reveal the relevance of the research topic and justify its choice, the following works were used as sources: PEFA 2009, 2016, Curristine et al. 2007, Global Financial Management Leaders Survey 2015.

Thus, in particular the source of PEFA 2009, 2016, is a methodological guide for assessing the quality of financial management in the public sector, describes its key elements and indicators of evaluation.

The article by Curristine et al. (2007), briefly discusses potential key institutional factors that can contribute to improving the efficiency of the public sector. The authors argue that there is enough evidence that some institutional variables help improve efficiency, mainly: functional and political decentralization to subnational governments; certain human resource management practices; and scale up operations. However, the most notable conclusion is the lack of empirical data and a systematic assessment of the effect of institutional variables on performance. (Curristine et al. 2007: 32)

Further, literature review is presented in the context of scientific issues studied in the "Research Questions" section of this paper.

\section{The Definition of Public Financial Management (PFM)}

Any research requires clarification of the definitions used in it. That is why at the beginning of the paper the analysis of the existing definitions of public finance management was conducted.

Thus, the existing definitions of financial management, formulated by researchers (Erasmus and Visser 2002), practitioners (Lawson 2015), found in the methodological literature (PEFA 2016) and reference literature (Order of the Ministry of Finance of Russia 2017) were analyzed. The analysis made it possible to identify the shortcomings of the existing definitions of the PFM and to formulate the author's definition.

\section{Finance Management Cycle in Public and Privet Sector of the Economy}

In the context of this research topic, it is useful to study the elements of the financial management cycle in the public sector. 
The most successful publication covering the content of the financial management cycle, in the opinion of the author of this paper, is the publication (Lawson 2015).

In addition to this, a comparative analysis was conducted of the elements of the financial management cycle in the public and private sectors of the economy. Analysis of the elements of the financial management cycle in the private sector is based on the practical experience of the author of this paper.

\section{Key Elements of the PFM System}

For a more detailed analysis of key elements of public sector financial management that contribute to the efficient management of public finances, studies have been conducted (Rakner et al. 2004) and Killick (2005).

The analysis of the above sources allowed to focus on the gap between the legally defined principles of public finance management and informal practices that simulate the process of cost allocation in accordance with the budget estimates.

PEFA (Public Expenditure and Financial Accountability 2016) and Guthrie (2005) were used to investigate the size and order of the public sector financial management system. The study of these sources allowed us to determine the key elements of the PFM system, the presence of which will allow increasing its efficiency (PFM system).

\section{Effective PFM System and Its Objectives}

Key aspects of the PFM system have been identified and main objectives were made possible by examining the PFM practice works (Lawson 2015).

\section{Different Approaches to PFM Reform}

A detailed analysis of PFM reforms and existing approaches to revenue and expenditure management in the public sector was facilitated by the work (Review of Public Financial Management Reform Literature 2009).

This paper explores the experience of reforming public financial management and was commissioned by DFID on behalf of the Ministry of Foreign Affairs of the Netherlands, the Swedish International Development Cooperation Agency (SIDA), Canadian International Development Agency (CIDA) and the African Development Bank (AfDB). This review will be useful to all researchers interested in the issues of reforms in the management of public finances and their evaluation.

\section{Factors Affect the Effectiveness of PFM Reforms}

Successful implementation of reforms in the PFM in each country requires certain resources and capacities. The work (Olander 2007) describes four interrelated elements that need to be considered when assessing and developing the capacity of a PFM. 


\section{$\underline{\text { PFM Issues and Opportunities }}$}

In addition to the traditional and current problems faced by all subjects related to the management of public finances, there are problems caused by globalization, new technologies (blockchain) and the informatization of society.

To conduct a risk analysis and challenges that need to be considered when managing finances in the 21st century, work was useful (Baubion 2013).

An invaluable contribution was made by work (Berryhill et al. 2018) on the use of blockchain technology in the public sector.

In covering questions about open government data (CRP), the work of (Ubaldi 2013) was helpful.

\section{Research Methods}

The main method of this scientific research was to review scientific sources (such as books, journal articles, guidelines, laws and abstracts) on the topic of publication. This review was aimed at analyzing, interpreting and critically evaluating the literature. Sources were synthesized to identify patterns, conflicts, and gaps. As a result, the author of this article shows the state of modern knowledge regarding the problems of research.

\section{Research Questions}

\section{The Definition of Public Financial Management (PFM)}

Public Financial Management (PFM) has seen rapid innovation over the past decade. Once focused narrowly on budgeting, PFM's scope has expanded dramatically, drawing new ideas and reforms from all corners of economics, political science, accounting and public administration. Its evolution has long to run but has already resulted in the emergence of, what the IMF describes as, 'ground-breaking' multidisciplinary public financial management practices. (Global Financial Management Leaders Survey 2015).

Any scientific study requires clarity of the key definitions that are used in it. It should be noted that there is the lack of an unambiguous approach to the definition of financial management in the public sector to date.

Table 1 contains several definitions of PFM. The first three definitions are taken from different sources. Typically, they contain information that PFM is a set of established rules, tools and processes. Existing definitions of PFM do not contain the objective of managing financial resources and do not take into account the risks associated with this process. 
Table 1. Analysis of Definitions of Public Financial Management

\begin{tabular}{|c|c|}
\hline Sources of definitions & Definitions \\
\hline PEFA $^{1}$ & $\begin{array}{l}\text { System of tools for assessing public finances within the four } \\
\text { stages of the budget process, aimed at achieving three main } \\
\text { results: overall budgetary discipline, strategic sharing of } \\
\text { resources, efficient use of resources to provide services. }\end{array}$ \\
\hline Erasmus and Visser ${ }^{2}$ & $\begin{array}{l}\text { The activities of civil servants, including decision-making } \\
\text { and other functions that allow to determine the optimal } \\
\text { ways of using limited resources for effective achievement } \\
\text { of political goals. }\end{array}$ \\
\hline Lawson $^{3}$ & $\begin{array}{l}\text { PFM is the set of laws, rules, systems and processes used by } \\
\text { sovereign nations (and sub-national governments), to } \\
\text { mobilize revenue, allocate public funds, undertake public } \\
\text { spending, account for funds and audit results. }\end{array}$ \\
\hline $\begin{array}{l}\text { Ministry of Finance of } \\
\text { Russian Federation }\end{array}$ & $\begin{array}{l}\text { A set of processes and procedures that ensure the } \\
\text { effectiveness and performance of the use of budgetary funds } \\
\text { and cover all elements of the budget process (budget } \\
\text { planning, budget execution, accounting and reporting, } \\
\text { internal control and audit). }\end{array}$ \\
\hline Author's Definition & $\begin{array}{l}\text { A system of principles and methods for the development } \\
\text { and adoption of managerial decisions by public authorities } \\
\text { and non-profit organizations regarding the formation, } \\
\text { distribution and effective use of financial resources with the } \\
\text { aim of improving the well-being of the country's population, } \\
\text { involving the systematic monitoring of these decisions, as } \\
\text { well as identifying emerging risks and the development of } \\
\text { measures to prevent them. }\end{array}$ \\
\hline
\end{tabular}

Therefore, based on the analysis of the existing definitions of the PFM, the author of this paper proposed his own definition, which eliminated the shortcomings mentioned above.

\section{Finance Management Cycle in Public and Privet Sector of the Economy}

While PFM definitions continue to vary, it is increasingly recognized that it covers not only technical accounting issues but also overall taxation, costs and debt management of the government, which in turn affects the allocation of public financial resources and income distribution. There is also a tendency to the fact that this is not a purely technical system or a set of subsystems, but a system of multiple role players, complex relationships and dynamic and interrelated processes, as shown in Figure 1.

\footnotetext{
${ }^{1}$ PEFA Assessing Public Financial Management. Washington DC 20433, USA, February. A Framework for 2016.

${ }^{2}$ Erasmus and Visser (2002: 983).

${ }^{3}$ Lawson (2015).

${ }^{4}$ Order of the Ministry of Finance of Russia from 16.12.2017 № 62n "On the organization of monitoring the quality of financial management, implemented by state administrators of budget funds of the federal budget".
} 
Figure 1. Finance Management Cycle in Public and Privet Sector of the Economy

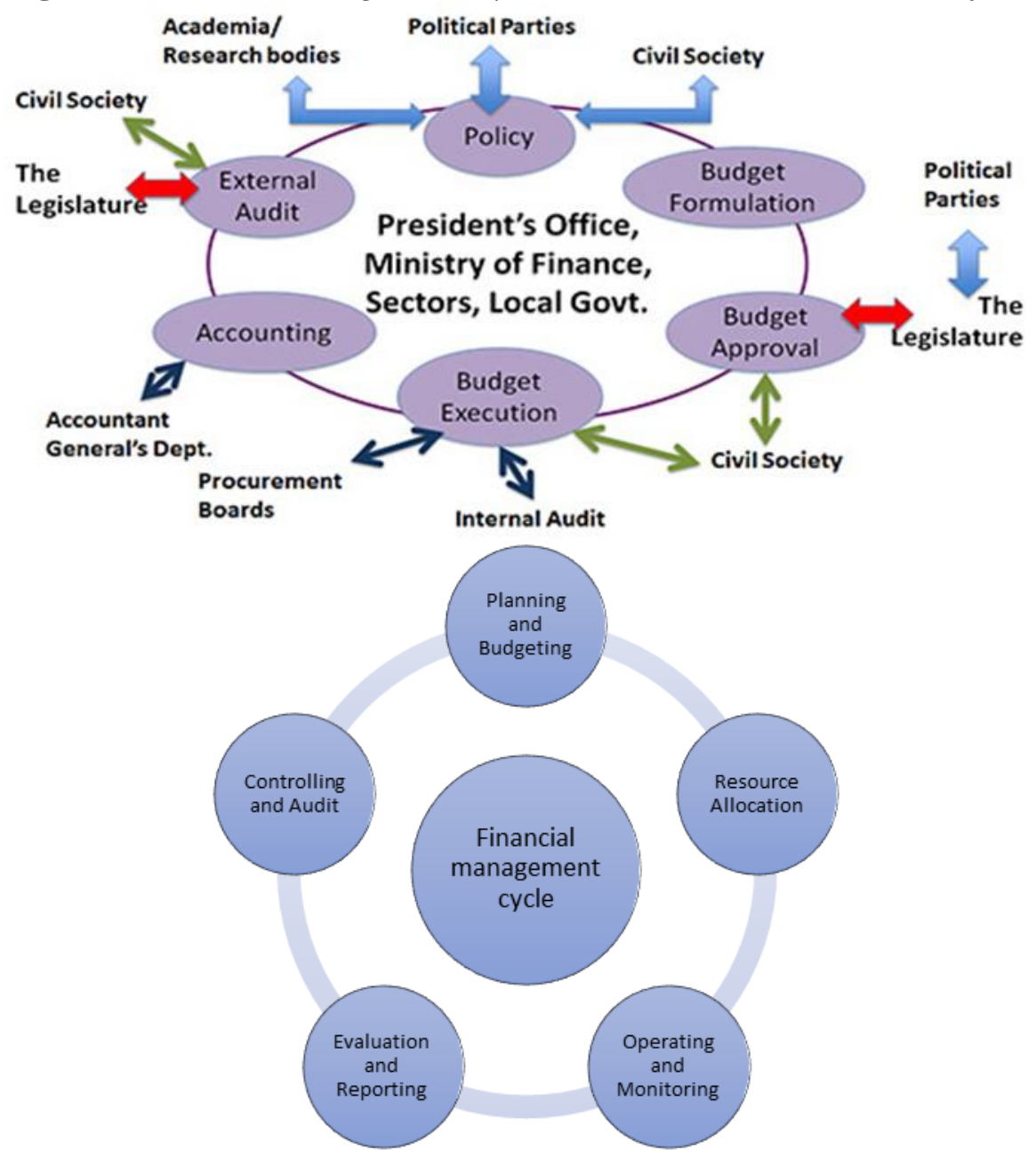

Source: Lawson (2015) \& Author.

Comparative analysis of PFM and FM cycles allows to draw a conclusion about the similarity of the financial management process itself. So, both cycles include the planning and budgeting phase, the budget approval phase, the accumulation and retrieval phase of the resources needed to achieve the goals and objectives, the accounting and reporting phase, the monitoring phase, and the auditing phase.

However, if we compare the participants taking part in these processes, we will notice that the participants in the PFM are much more than in FM. The results of the analysis are shown in Figure 2. 
Figure 2. Comparative Analysis of Actors Involved in Financial Management in the Public and Private Sectors of the Economy

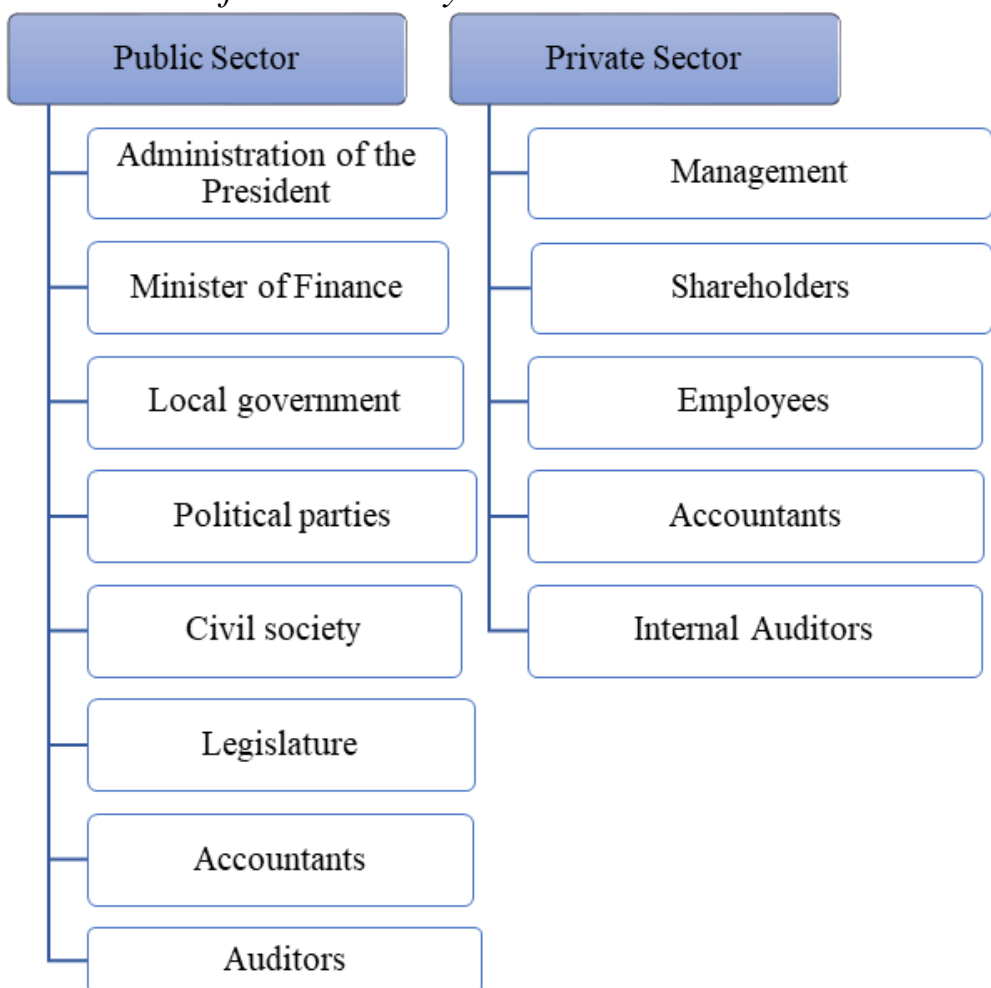

Source: Compiled by the Author.

A significant number of actors involved in the public finance management cycle require coordination, approval and evaluation of the actions and outcomes of these actions at each stage of the PFM cycle from the point of view of each participant. Each participant in this process has its own interests to its results and an understanding of its effectiveness. The complexity of harmonizing actions and, taking into, account the views of all actors is in itself a challenge. It is necessary to ensure the effectiveness, transparency and accountability of the PFM process.

Describing the role of each actor in this process, it should be noted the unqualified importance of professional specialists in this process, such as accountants, auditors, lawyers, managers, procurement specialists and taxes. Thanks to the efforts of these specialists, a complex PFM process can technically be implemented.

A significant role in this process belongs to the central government of each jurisdiction and to local governments. The role of the government as an executive body in this process is to distribute public financial resources for various purposes.

A special role in this process belongs to civil society. The requirements of civil society to increase transparency and accountability in the management of public financial resources are constantly increasing and are a challenge now, which the government must constantly respond to. 


\section{Key Elements of the PFM System}

It should be noted that due to the politicized nature of the process of agreeing, adopting and approving the budget, some researchers note a gap between official institutions (how they should work) and informal practices (how everything works). Informal practices often "make the system work", but, can slow development and generate corruption. Rakner et al (2004: 54) describe the budgetary process as a "theater", which masks the actual allocation of resources and expenditure patterns. Killick (2005) concludes that this undermining of official institutions leads to large deviations between budget estimates and actual expenditures. The reasons that led to this you can see on Figure 3.

Figure 3. The Reasons of Large Deviations Between Budget Estimates and Actual Spending

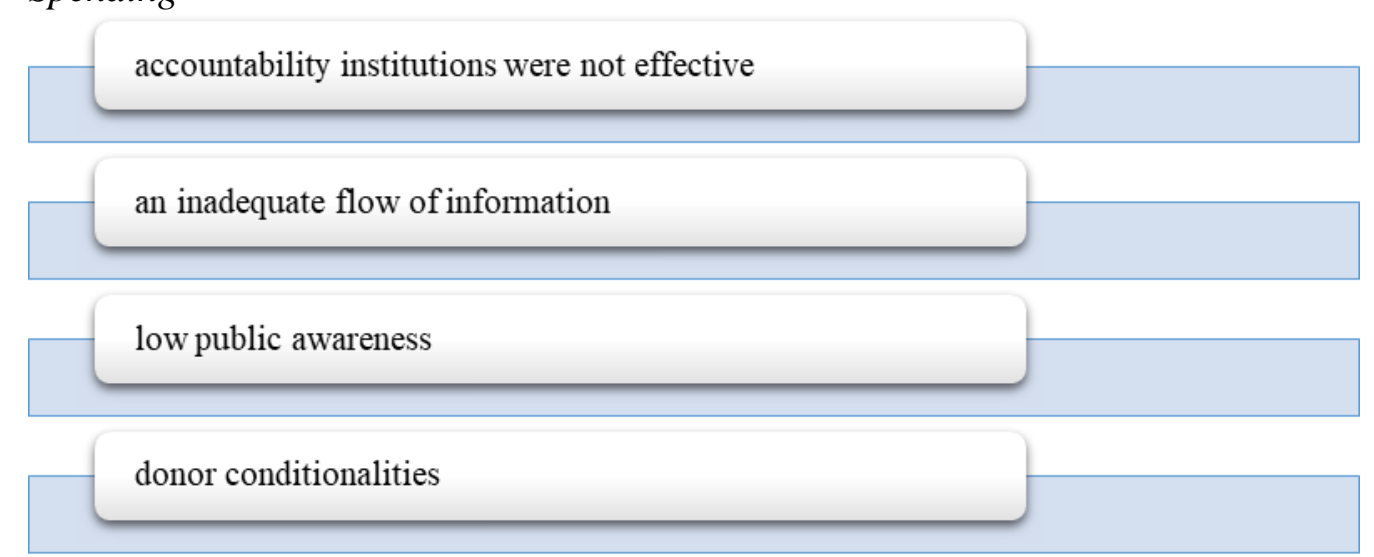

Source: Compiled by the Author.

To solve these problems, key elements of the PFM system were identified. We investigated the critical dimensions identified by PEFA (Public Expenditure and Financial Accountability 2016) ${ }^{5}$ and Guthrie (2005), compared them and concluded that most of these key elements coincide, but some differences were found.

PEFA identifies the critical dimensions of an open and orderly PFM system. They are:

i) budget comprehensiveness transparency;

ii) policy based budgeting;

iii)predictability and control in budget execution;

iv) accounting and reporting;

v) external scrutiny and audit;

vi) budget credibility.

It is important to remember that public finance comprises a complex set of closely interrelated subsystems (e.g. tax and customs, budgets, expenditure, inter-

${ }^{5}$ https://pefa.org/content/pefa-framework. 
governmental finance, parliamentary oversight, internal and external financial control). Reforming a particular subsystem may have consequences for a number of related areas. Guthrie identifies five key dimensions to New $\mathrm{PFM}^{6}$ :

i) changes to financial reporting systems (cash to accrual);

ii) devolution of budgets;

iii)market based costing and pricing systems;

iv) a performance measurement approach and

v) performance based (internal and external) auditing.

We compared the key elements of PFM from different sources and came to the conclusion that the content of most elements coincides. For example, in both analyzed sources there are elements such as budget transparency, accountability and reporting, control and audit. Despite the fact that PEFA alone does not include such an element as an efficiency measure, it is certainly present, because "PEFA is a methodology for assessing public financial management performance. It identifies 94 characteristics (dimensions) across 31 key components of public financial management (indicators) in 7 broad areas of activity (pillars)" (Figure 4).

Figure 4. Seven Areas of Performance Assessment of Public Financial Management on Based of Methodology for Assessing by PEFA

\begin{tabular}{|l|}
\hline Transparency of public finances \\
\hline Management of assets and liabilities \\
\hline Policy-based fiscal strategy and budgeting \\
\hline Predictability and control in budget execution \\
\hline Accounting and reporting \\
\hline External scrutiny and audit \\
\hline
\end{tabular}

Source: Compiled by the author on based PEFA $(2016)^{7}$.

The PEFA program provides a framework for assessing and reporting on the strengths and weaknesses of public financial management (PFM) using quantitative indicators to measure performance. PEFA is designed to provide a snapshot of PFM performance at specific points in time using a methodology that can be replicated in successive assessments, giving a summary of changes over time. $^{8}$

\footnotetext{
${ }^{6}$ Review of Public Financial Management Reform Literature (2009). London: DFID. ${ }^{7}$ https://pefa.org/sites/default/files/PEFA_2016_Framework_Final_WEB_0.pdf.

${ }^{8}$ https://pefa.org/what-pefa.
} 
Returning to the comparison of key elements, it is necessary to recall that the Guthrie selects an element "market based, costing and pricing systems", that PEFA does not have.

With regard, to the use of market pricing in the public sector, each jurisdiction solves this problem in its own way. For example, the cost of the educational service provided by the university in the Russian Federation on a budgetary basis is calculated at standard costs approved by the Ministry of Science and Higher Education of the Russian Federation. At the same time, the price of an educational service provided on a paid basis cannot be lower than the price of a similar service on a budgetary basis. The system of market pricing in this case is practically impossible to apply, because if the demand for this educational service is small, the market price may be lower than the standard cost, which cannot be applied, because this is a violation of the law.

Effective PFM System and Its Objectives ${ }^{9}$

Effective Public Financial Management (PFM) systems are required to maximize the efficient use of resources, create the highest level of transparency and accountability in government finances and to ensure long-term economic success, as shown in Figure 5.

Figure 5. Key Aspects of Effective Financial Management

required to maximise the
efficient use of resources $\quad \begin{gathered}\text { create the highest level of } \\ \text { transparency and } \\ \text { accountability in government } \\ \text { finances }\end{gathered}$ success

Source: Compiled by the author on the basis of Lawson (2015).

From the requirements of effective financial management, we can formulate its objectives, which are presented below in Figure 6.

\footnotetext{
${ }^{9}$ Measuring the effectiveness of any process, especially such a complex one as financial management in the public sector, deserves close attention and special research. Detailed consideration of approaches to measuring PFM performance is not expected in this article.
} 
Figure 6. Objectives of PFM System

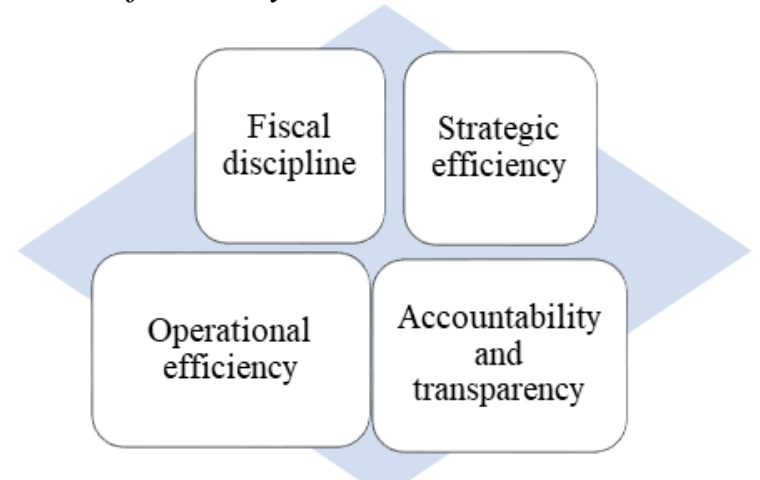

Source: Compiled by the author on the basis of Lawson (2015).

The primary objective of the PFM system is to maintain budgetary discipline. Fiscal discipline should ensure that the level of tax collection and public expenditure is consistent with the objectives of the budget deficit. It should ensure that government borrowing is not generated.

Secondly, the PFM system should ensure the efficiency of the allocation of public resources, namely the compliance of allocated state resources with strategic state programs.

Thirdly, this PFM system should provide operational efficiency, namely, the achievement of a price-quality ratio in the delivery of services.

Finally, the PFM system should be transparent, open, with the obligatory presence and control and accountability of the persons responsible for the use of public financial resources.

To achieve the goals of financial management in the public sector at the current stage, many governments are implementing PFM reforms. To understand the essence of these reforms, the historical aspect of the transformations in the field of public finance was considered.

\section{Different Approaches to PFM Reform}

During the seventies and eighties, OECD countries (the Organization for Economic Cooperation and Development) and some developing countries began to review the management of their public sector, as shown in Figure 7. By the mid1990s, scientists and practitioners realized that the portability of these ideas to developing countries was facing challenges.

At the same time, the World Bank has proposed its own approach to assisting in implementing PFM reforms to countries that are concerned about the implementation of such reforms, and has developed its own approach to public expenditure management (PEM), as shown in Figure 8. 
Figure 7. Drivers of PFM Reforms

\begin{tabular}{|c|c|}
\hline Financial crisis & $\begin{array}{l}\text { - Tanzania, UK, Canada, Argentina, Asian } \\
\text { economies }\end{array}$ \\
\hline Political change & $\begin{array}{l}\text { - South Africa, the countries of the former Soviet } \\
\text { Union }\end{array}$ \\
\hline $\begin{array}{l}\text { Changes in public expectations / } \\
\text { public pressure }\end{array}$ & - Great Britain, Canada, Colombia, Guatemala \\
\hline Post-conflict conflict & $\begin{array}{l}\text {-Rwanda, Burundi, Mozambique, Afghanistan, } \\
\text { Liberia, Timor-Leste }\end{array}$ \\
\hline New technologies & $\begin{array}{l}\text {-E-procurement systems in Chile, Mexico, Korea } \\
\text { and the Philippines }\end{array}$ \\
\hline Regional needs & $\begin{array}{l}\text { - The West African Economic and Monetary Union } \\
\text { (WAEMU), the accession of the European Union } \\
\text { (EU) }\end{array}$ \\
\hline Donor pressure & $\begin{array}{l}\text { - Heavily Indebted Poor Countries Initiative (HIPC) } \\
\text { and other donor requirements }\end{array}$ \\
\hline
\end{tabular}

Source: Compiled by the author on basis Review of PFM Reform Literature (2009) ${ }^{10}$

Figure 8. Conceptual Changes in Financial Management in the Public Sector

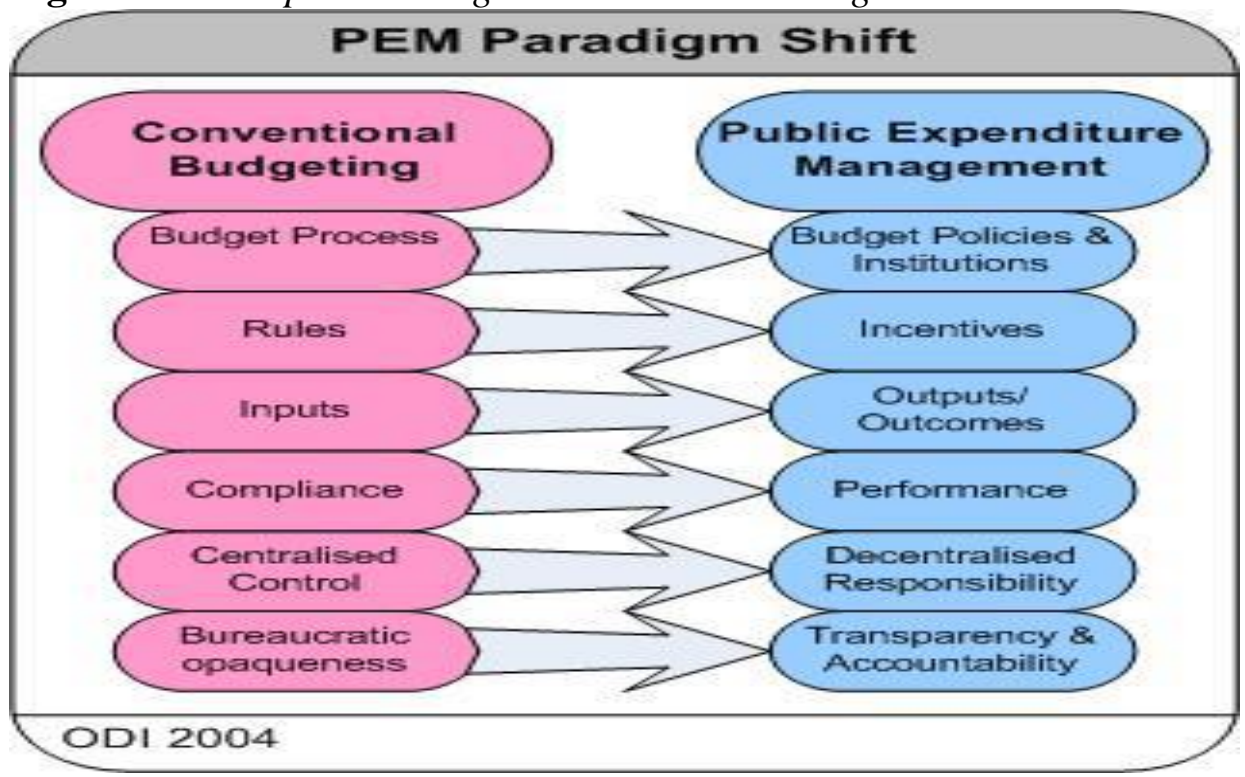

\footnotetext{
${ }^{10}$ Review of Public Financial Management Reform Literature, Evaluation Report EV698, 2009, p.4. Available at: https://bit.ly/2YHLyzC.
} 


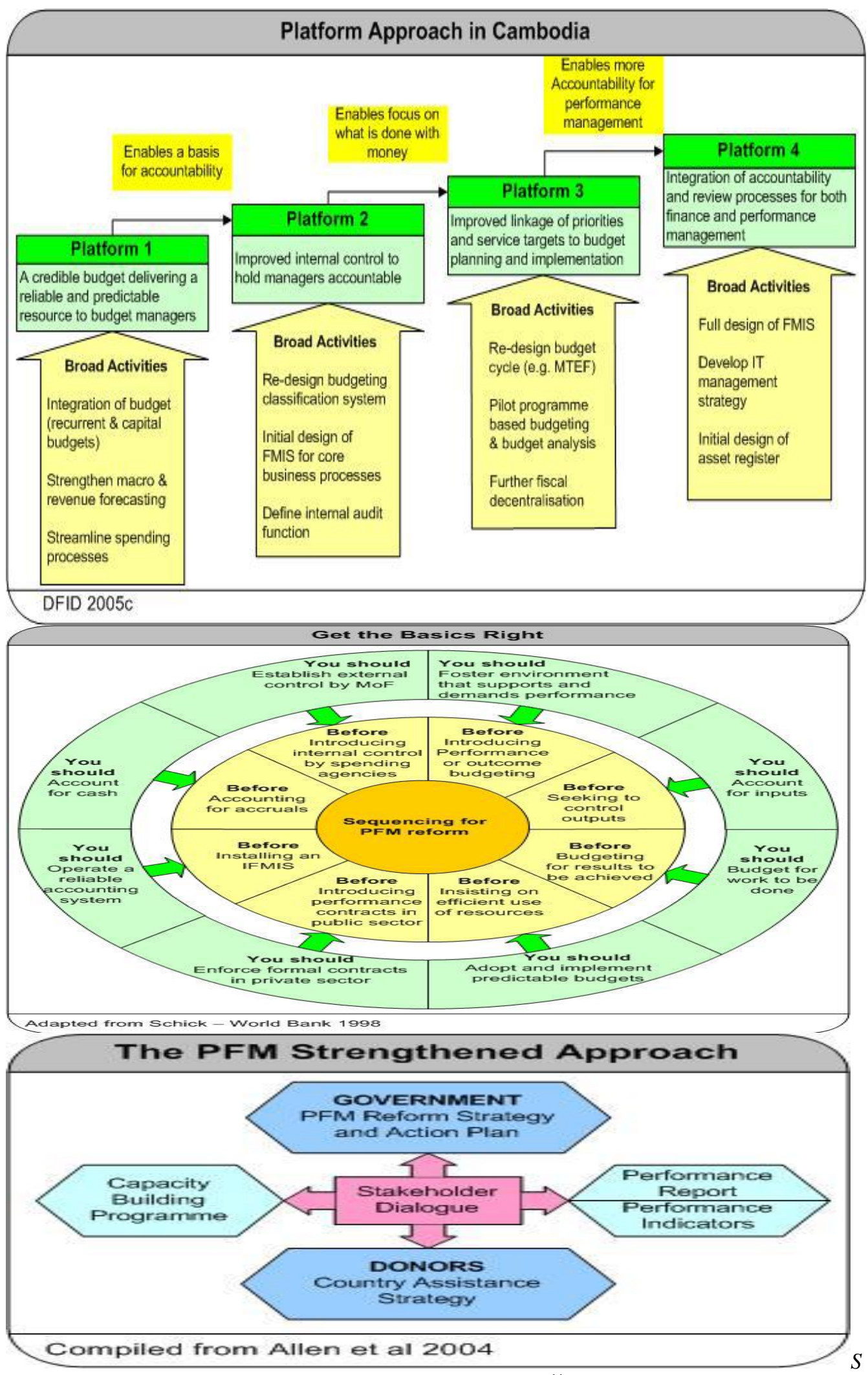

Source: Review of PFM Reform Literature $(2009: 9,10,12)^{11}$

${ }^{11}$ https://bit.ly/2YHLyzC. 
As shown in Figure 8, the emphasis in the approaches to the implementation of the PFM reforms has shifted to take into account the significance of the complex network of actors and institutions involved in the budget process and to link costs with measurable results.

The approach to public expenditure management focuses on incentives and informal practices and budgeting. Supporters of the approach emphasize that in order to improve public expenditure management, changes are required in budget institutions, the role of trusts and supervisors, the rules by which they declare, allocate and use resources and the information available to them.

By early 2000, governments and donors from developing countries had begun to wonder why PFM reforms had achieved only limited success. The subsequent search for answers led to the following conclusions.

First, the budget is a political process, not just a technical one, and that in many countries informal behavior and practice abolish formal ones.

Secondly, these reform programs require countries to participate and a political commitment to achieve real sustainable progress.

And thirdly, this coordination and harmonization of donors is important. This improved understanding has led to the development of three different but potentially mutually reinforcing approaches to PFM reform, namely the political economy model, the platform approach is more focused on the consistency of reforms in a specific country context and the strengthened approach that determines the relationship and role of all actors in reform in the field of public finance.

The above models and approaches are mainly applied to the reform of expenditure management, rather than to revenue management (Figure 9). To manage revenues, a different set of models was proposed.

With regard to the four main theoretical approaches to public expenditure management, it can be noted that they have an impact on tax revenues. These:

(i) Approach to management in the public sector of the economy, which emphasizes the effectiveness and fairness of taxation systems (microeconomic approach);

(ii) The macroeconomic approach, which emphasizes the impact of the taxation system on the distribution of household incomes, the level of savings, inflation and public debt;

(iii) an administrative approach that emphasizes the efficiency of the costs of administering taxes;

(iv) A political approach that recognizes the inherent political nature of the taxation process.

Because of the politicized approach to managing public revenues, this article excludes consideration of policy-related approaches. 
Figure 9. Approaches to PFM Reform to Expenditure and to Revenue

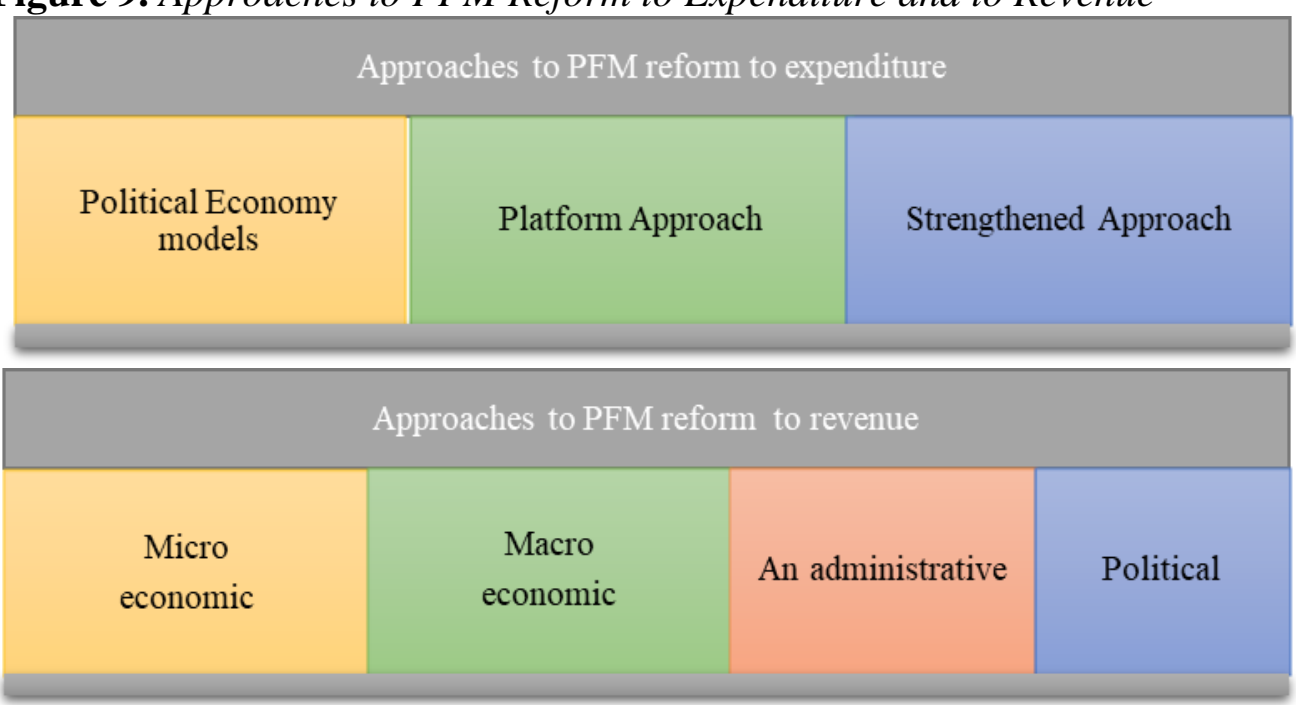

Source: Compiled by the author.

\section{Factors Affect the Effectiveness of PFM Reforms}

Successful implementation of PFM reforms requires certain opportunities, including available resources in the country for the implementation of PFM reforms (capacity).

The United Nations Development Program (UNDP) defines capacity as "the ability of individuals, institutions and societies to perform functions, solve problems, establish and achieve goals." Olander (2007) describes four inter-related elements that need to be considered when assessing and developing PFM capacity (Figure 10).

Figure 10. PFM Capacity Assessment

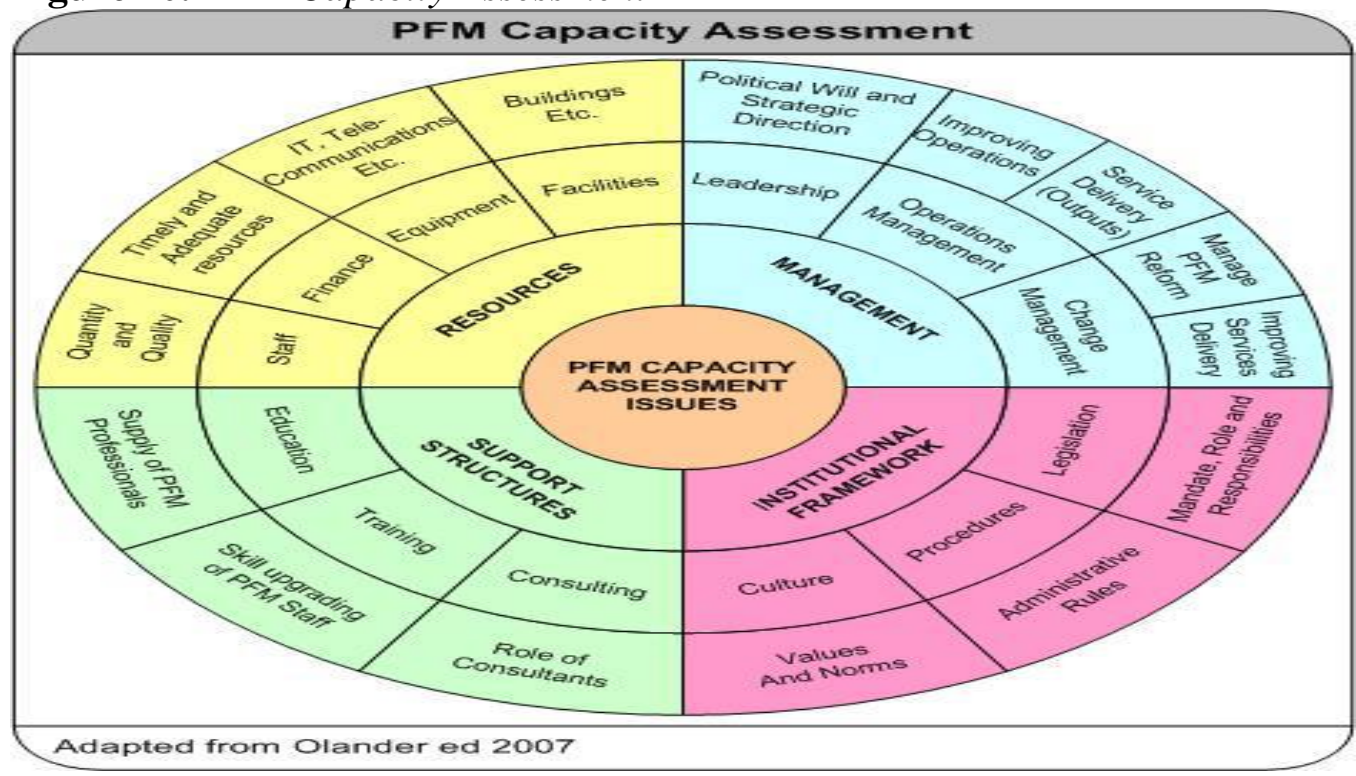

Source: Compiled by the author on basis Review of PFM Reform Literature (2009). 
First, resources include the availability of a sufficient number of staff with professional skills, the availability of sufficient and timely financial resources, equipment and facilities.

Secondly, a management style is considered that includes leadership and political will, operational management and change management of the PFM reform program.

The third element implies the existence of an institutional framework, takes into account legislation, procedures and organizational culture.

The latter element refers to support structures, including the role of higher education institutions and professional organizations, training through training and the role of consultants.

\section{PFM Issues and Opportunities}

In addition to the problems associated with a lack of capacity for PFM reform, it is necessary to remember the processes taking place in the economy and the world that are beyond control and management and that affect PFM.

Obviously, countries implementing PFM reforms may suffer from a lack of resources, weak governance, a lack of readiness for an institutional reform structure and a lack of a supportive structure. The listed problems, of course, are problems that make PFM reforms difficult, but these problems are amenable to control and management. Uncontrolled problems include, first of all, globalization and its consequences, which are listed in Figure 11.

\section{Figure 11. Challenges to PFM Caused by Globalization and Other Factors}

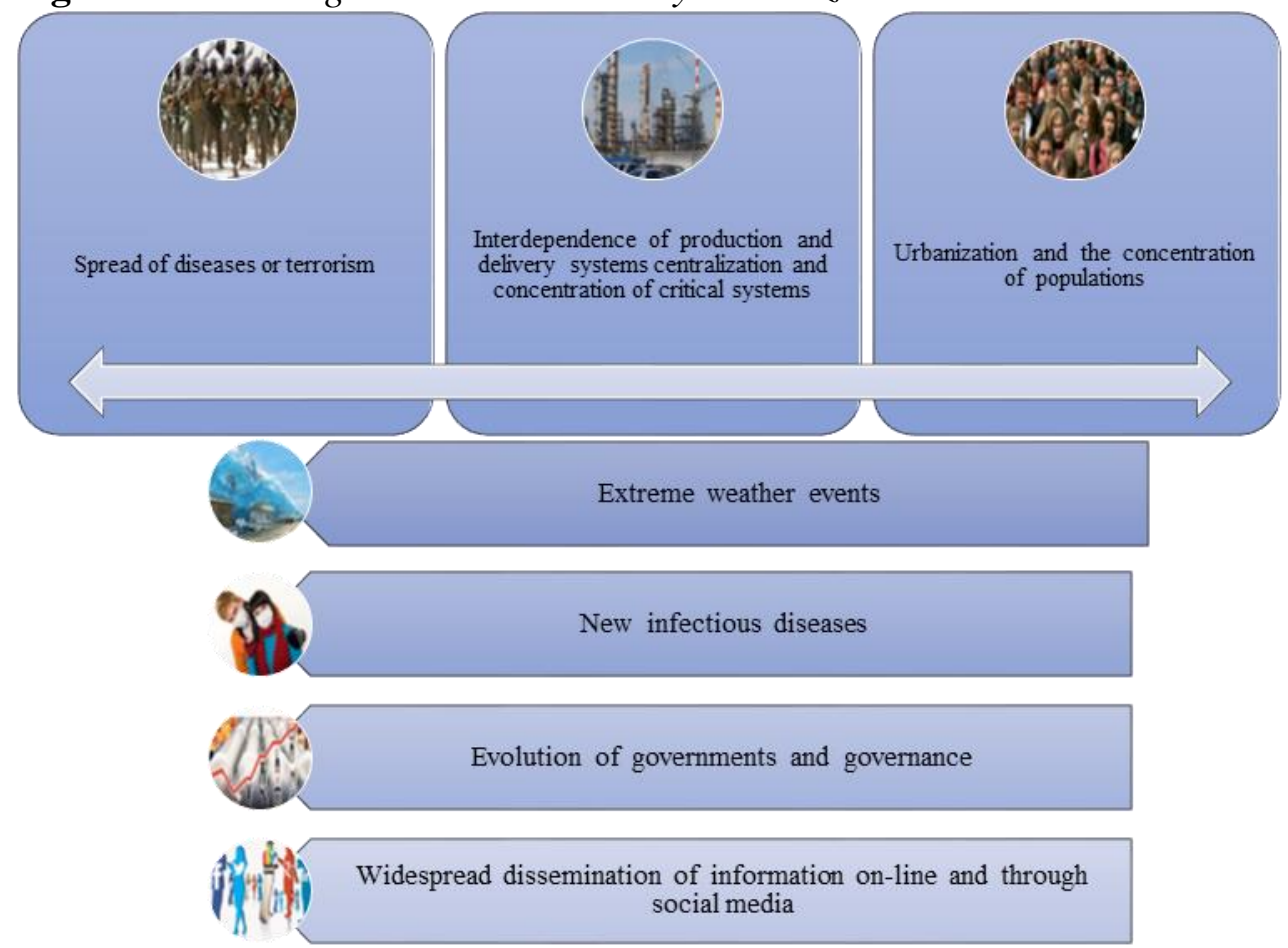

Source: Compiled by the Author. 
Today, the advantages of globalization are widely used, namely: better allocation of resources, higher production level and standard of living, and greater access to foreign goods and services.

At the same time, globalization is also perceived as increasing inequality within and between countries, easing weaknesses, the threat of employment of unskilled and illiterate workers and their standard of living, and thus increasing poverty. In fact, the process of globalization and the market forces that accompany it must be properly developed and used to become a comprehensive force for sustainable and human-centered development. In these efforts, governments, international financial organizations, the private sector, NGOs and civil society have to make serious efforts and play a more constructive role in cooperation so that globalization works for the benefit of people in a spirit of partnership.

To the extent that globalization is perceived as a factor in the deterioration of income distribution, it seems that it increases the need for government regulation, while at the same time it reduces the government's ability to intervene because of the reduced availability of financial resources. Developing countries and countries with economies in transition may need to undertake major public expenditure reforms to improve competitiveness in the world market and reduce structural unemployment. Reforms in public financial management that have been implemented in some countries over the past two decades show that improving budget transparency by strengthening budgetary mechanisms, measuring results and effectiveness with respect to objectives, public accounting and performance audit, civil service reform will contribute to effective allocation of resources and increase confidence in the budget process. Successful financial management reform also requires macroeconomic control over the budget balance, prioritization of expenditures, a consistent legal and regulatory framework, financial transparency and public participation in decision-making, In particular, the state administration in the 21 st century will have to activate public interest and public feedback into policy-making. The accessibility, quality and accessibility of information and fiscal data are important for empowering citizens and their participation in the decision-making process that can be realized through greater transparency and an effective accountability framework.

In our opinion, taking risks into the management of public finances is an adequate tool that will reduce the negative consequences of globalization.

Globalization, recent crises and natural disasters are challenging political leadership and risk management in many countries, often due to unforeseen or unforeseen circumstances, and due to weak links and disruptions in the flow of information.

These problems require governments to adapt their processes, structures, tools and equipment to manage the destructive events of a new form and allocate financial resources for these purposes. The problems faced by risk managers today are listed below in Figure 12: 
Figure 12. Challenges for Government Risk Managers in XXI Century

Source: Baubion (2013: 8).

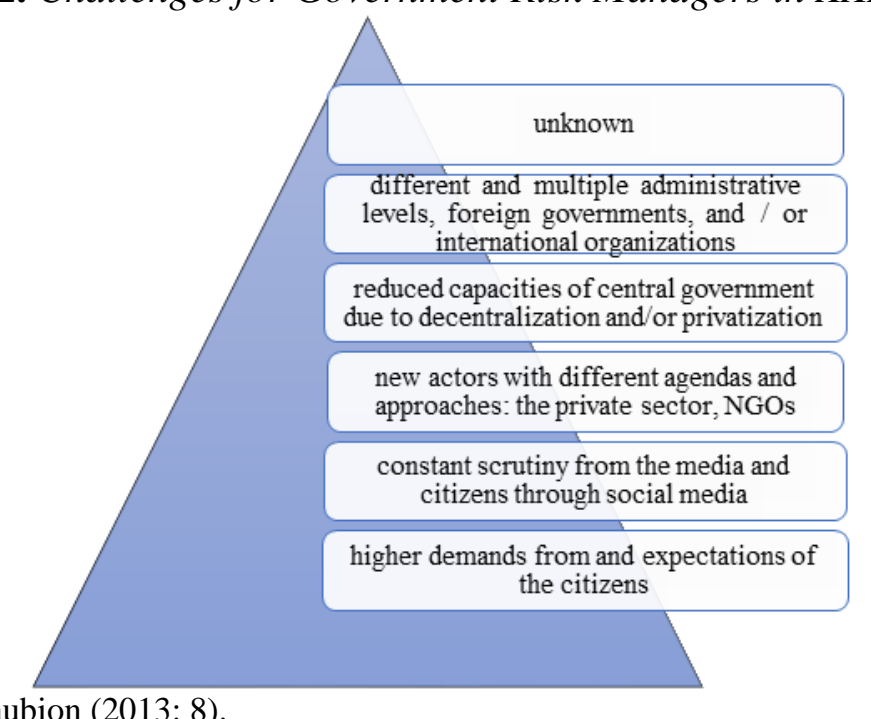

At the same time, governments need to maintain capacity to deal with more traditional crises as in the past. The innovations required to adapt to new features of crises and societies are not replacements for, but rather complements to existing capacities and can be built on them.

Table 2 shows the main differences between the traditional approach to crisis management and the approach that allows coping with new crises. While governments need to adapt their crisis management capabilities to the characteristics of new crises, develop new approaches and tools, they must also maintain the ability to cope with classic crises.

At the present stage of financial management in the public sector, managers face to face with challenges in the field of technology and information society.

First of all, we mean Blockchain technology. The effect of blockchains in the public sector is at best misunderstood and most often ignored.

As illustrated on Figure 13, Blockchain technology's underpinning assumption is that all transactions will be visible to all nodes in the system at all times. To achieve this, in general, all nodes hold identical 'ledgers' of transactions that are rapidly updated any time a new set of transactions is added. This enables a key feature of the Blockchain architecture: consensus models where nodes in the system confirm the validity of transactions that occur on the platform, and flag inappropriate dealings when necessary. 
Table 2. Comparative Analysis of the Traditional and New Approach to Risk Management

\begin{tabular}{|c|c|}
\hline Traditional Crisis Management & Dealing with Novelty \\
\hline \multicolumn{2}{|c|}{ Preparedness Phase } \\
\hline $\begin{array}{l}\text { Risk assessment based on historical } \\
\text { events }\end{array}$ & $\begin{array}{l}\text { Risk assessment includes horizon scanning, } \\
\text { risk radars and forward looking analysis to } \\
\text { detect emerging threats. Frequent updates } \\
\text { and different timescales, international } \\
\text { analysis sharing, multidisciplinary } \\
\text { approaches are key attributes }\end{array}$ \\
\hline Scenario based emergency planning & $\begin{array}{l}\text { Capability-based planning and network } \\
\text { building }\end{array}$ \\
\hline Training to test plans and procedures & $\begin{array}{l}\text { Strategic crisis management training to learn } \\
\text { agility and adaptability and create networks } \\
\text { and partnerships }\end{array}$ \\
\hline $\begin{array}{l}\text { Early Warning Systems based on } \\
\text { monitoring, forecasting, warning } \\
\text { messages, communication and } \\
\text { link with emergency response }\end{array}$ & $\begin{array}{l}\text { Strategic engagement from centers of } \\
\text { government }\end{array}$ \\
\hline \multicolumn{2}{|l|}{ Response Phase } \\
\hline Command and control system & $\begin{array}{l}\text { Crisis identification / monitoring: role of } \\
\text { expertise }\end{array}$ \\
\hline Standard Operating Procedures & $\begin{array}{l}\text { Flexible and multi-purpose crisis } \\
\text { management teams and facilities }\end{array}$ \\
\hline Strict lines of responsibilities & $\begin{array}{l}\text { Common concepts across agencies to inform } \\
\text { leadership with high adaptative capacities }\end{array}$ \\
\hline Sectoral approaches & $\begin{array}{l}\text { Similar tools and protocols that could be } \\
\text { utilised for multi-crisis }\end{array}$ \\
\hline Principle of subsidiarity & International co-operation \\
\hline \multirow[t]{3}{*}{ Feedback to improve SOPs } & Management of large-response networks \\
\hline & Ending crisis and restoring trust \\
\hline & Feedback \\
\hline
\end{tabular}

Source: Baubion (2013: 21).

Figure 13. Distributed Networks Compared to Centralised and Decentralized Networks

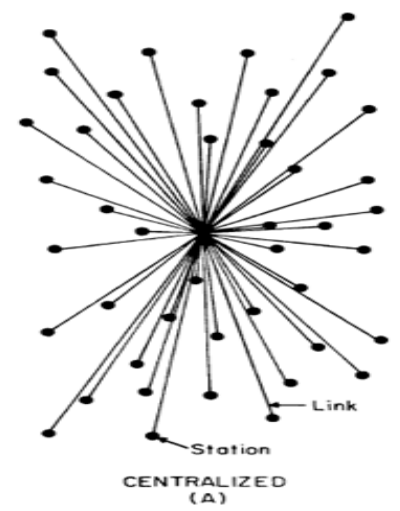

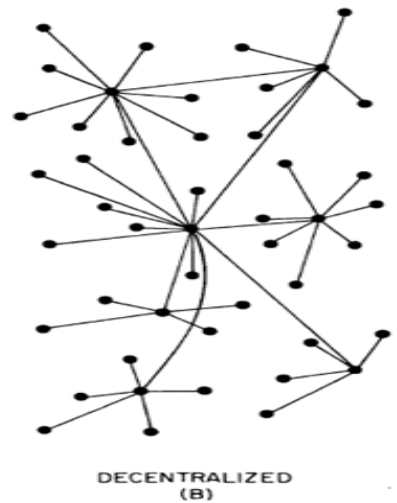

(B)

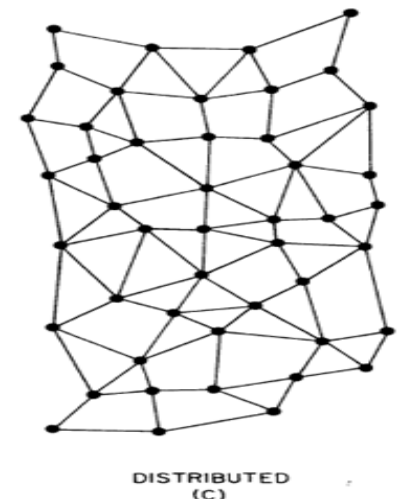

(C)

Source: Berryhill et al. (2018: 12) 
Although Blockchain technology developments have been most extensive in the financial services industry, the discussion and application of Blockchains is also rapidly emerging in the public sector. Governments are taking action to learn more about Blockchain technology and to introduce Blockchain conceptsand the associated opportunities and challenges - with policy-makers and civil servants.

Figure 14. Blockchain in the Public Sector

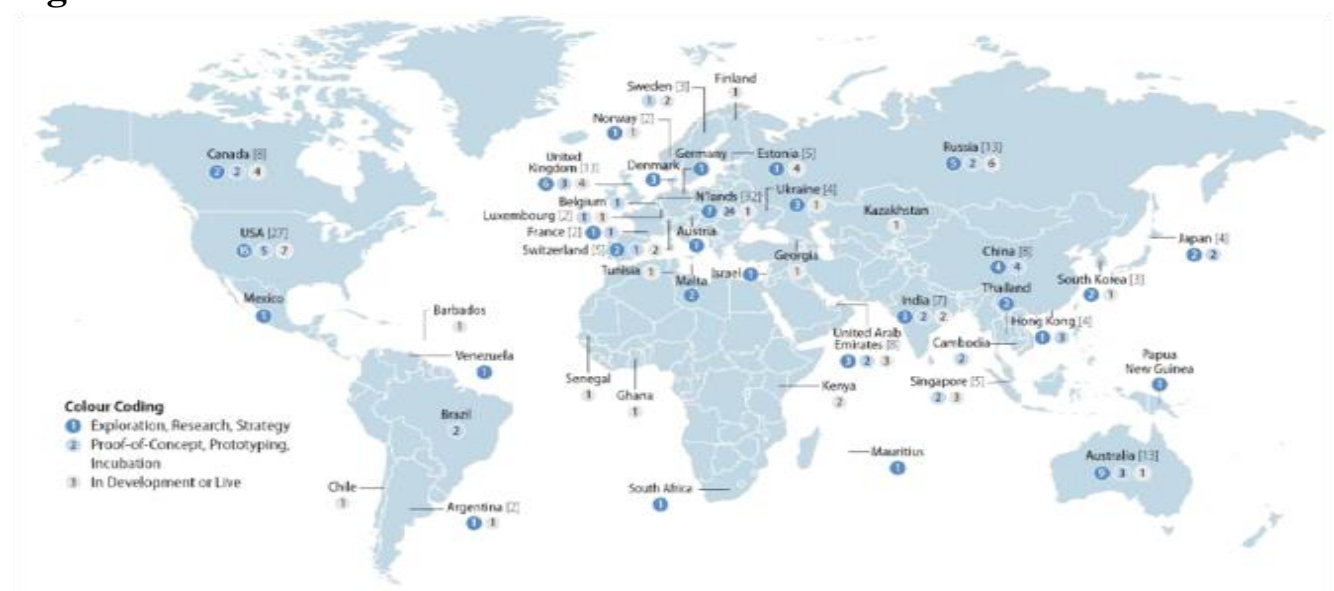

Source: Berryhill et al. (2018: 21).

As illustrated in Figure 14, at least 46 countries around the world have launched or are in the planning stages to launch over 200 Blockchain-related initiatives. Case studies on several of these initiatives are presented in Table 3.

Table 3. Top 10 Types of Projects and Industries Using Blockchain-Related Initiatives

\begin{tabular}{|c|c|c|}
\hline Rank & Types of projects (count) & Industries \\
\hline 1 & Strategy/Research (42) & $\begin{array}{c}\text { Government Services } \\
(173)\end{array}$ \\
\hline 2 & Identity (Credentials/Licenses/Attestations) (25) & Financial Services (73) \\
\hline 3 & Personal Records & Technology \& Internet of \\
Things (26)
\end{tabular}

Source: Berryhill et al. (2018: 22).

Obviously, Blockchains are simply permanent, unchanged and distributed transaction lists with a lot of technical capabilities to ensure that this list can be trusted. 
Now, due to the fact that governments are deeply focused on economic efficiency and accountability and regard these aspects as key characteristics of the state financial policy being formed, this technology certainly deserves a close study with a view to its possible use in solving various tasks in the area of public financial management.

From the already existing case studies, it can be said that Blockchain technology has the potential in the following areas of financial management in the public sector, listed below in Figure 15.

Figure 15. Opportunities of Blockchain in the Public Sector

Improve effectiveness

Source: Compiled by the Author on based Berryhill et al. (2018).

In addition to increasing government transparency and public awareness of government programs and activities, the discovery of data can also help gain information on how to improve the effectiveness of public financial management. Improving data transparency provides the basis for public participation and cooperation in creating innovative services. In addition, the openness of the data is expected to improve the decision-making process by both governments and individuals. In particular, it is expected that the public will be able to use government data to make informed and more accurate decisions and improve the quality of life.

At the same time, governments will be able to more easily access a wider range of different information contributing to making decisions in the credibility of which will be easily verified.

Finally, OGD is also seen as an important source of economic growth, new forms of entrepreneurship and social innovation.

However, it is worthwhile to express a warning, since the OGD remains an unexplored territory. Everything should have a reasonable limit. The disclosure of any information should be carefully balanced, especially that information that can damage public security and citizens' privacy.

The data must be relevant, easily accessible, usable and reused by all. It is important for Governments to draw public attention to the usefulness, relevance and accessibility of their data in order to ensure their continuous improvement and updating. Improved data accessibility can ensure closer cooperation with both 
governments and between government agencies and the wider society, including the private sector, civil society organizations and citizens. This stimulates a shift in the organizational culture of the public sector, not only to openness, transparency and accountability, but also to exchange, cooperation and wider involvement of the public. The two main elements of OGD are normally defined as follows (Figure 16):

Figure 16. The Elements of $O G D$

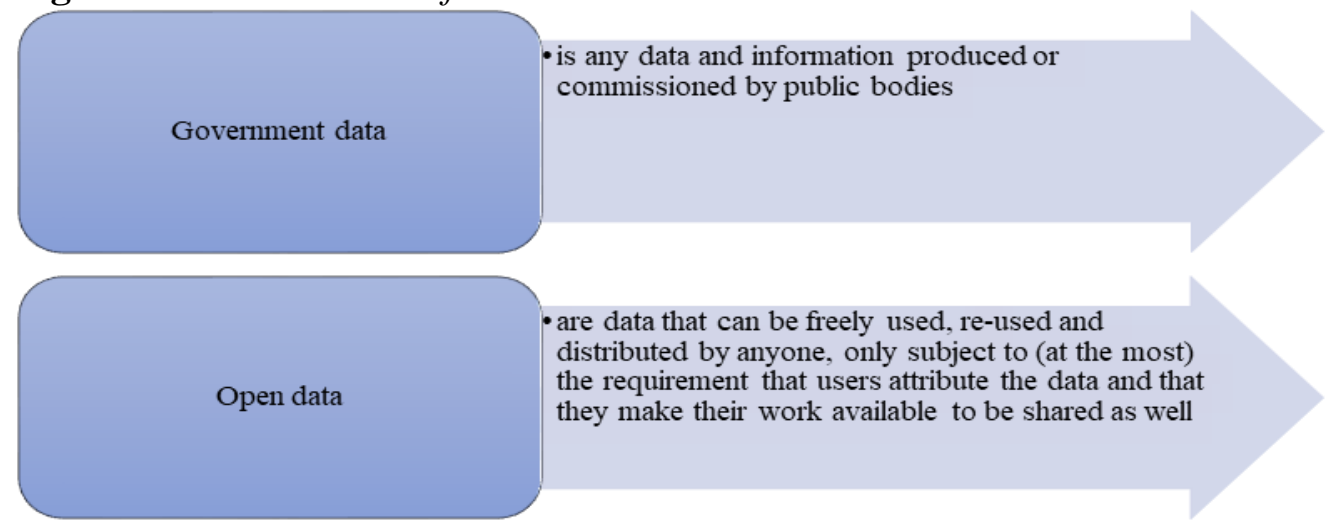

Source: Compiled by the Author based on Ubaldi (2013).

Examples of OGD initiatives listed on Figure 17 and include:

Figure 17. Opportunities of $O G D$

\begin{tabular}{ll|}
\hline Registers, patent and trademark information and public \\
tender databases
\end{tabular}

Source: Compiled by the author on the based Ubaldi (2013).

Below is a list of recognized main beneficiaries of OGD:

i) Government. At the macro level, OGD provides opportunities for new ways of making decisions and allocating resources to improve the overall efficiency of government operations (for example, accelerating efforts to reduce fraud and error, further progress in tax gaps) and to better deliver 
public services while improving the quality of government interaction and all other subjects interacting with him on various issues.

ii) Citizens. It is expected that the data of the open government will allow wider participation of the public in the development of measures to respond to public needs. The Internet portal illustrates the intersection of the mobile government and OGD. The discovery of public sector data (for example, crime rates, gas emissions, teachers per pupil in urban schools) makes citizens more informed and allow them to make more informed personal choices. To summarize, it can be argued that OGD can help improve the quality of life of the country's population.

iii) Civil society. Civil society initiatives that are based on OGD can be found in many countries. The overall objectives of these initiatives include demonstrating the benefits of OGD to the government and the public.

iv) Expansion of the economy, private sector and public services: OGD can stimulate a competitive market, for example, for public sector services. It is expected that the private sector (technology developers) will be one of the main users of the data sets for commercial exploitation of OGD. Stimulating profits can help stimulate innovation and experimentation, while it can be expected that better ideas will be emulated and improved, since no service provider has a monopoly on data.

Using Open Data does not guarantee transparency and accountability of the government. As stressed by Yu et al. (2012) "A government can be open, in the sense of being transparent, even if it does not embrace new technology, and a government can provide open data and still remain deeply opaque and unaccountable".

\section{Results}

The study revealed the factors adversely affecting the efficiency of public sector entities. The following factors can be attributed to them:

i) Issues of control and organization of production, including: the conditions of the "soft budget constraint" (subsidies, there is no threat of bankruptcy); there is no purpose of profit maximization; there are no incentives to improve efficiency; the difficulty of long-term investment planning; bureaucratic goals (maximizing the size of the organization); limitations on the type and quality of material costs (purchase specification); the impact of the policy, the political aspects of economic decision-making; a low level of risk-averse (emphasis on formal procedures).

ii) Features of stimulation of work of civil servants, including: a weak threat of dismissal; low wages compared with similar work in the private sector; the lack of incentive performance pay systems; the difficulty in determining the results of work of civil servants; corruption. 
iii) Features of industry competition, including: no competition (postal service); the conditions of the natural monopolies (the bureaucratic monopoly).

In addition to this, the results of this study include:

i) Based on the analysis of existing definitions of public financial management, its author's definition is given;

ii) Based on a comparative analysis of management cycles in the public and private sectors of the economy, common and different features of both management cycles were identified;

iii) The revealed features of the public finance management system have made it possible to identify its key elements;

iv) The author's view on an effective financial management system in the public sector is presented, and its objectives are defined;

v) The historical aspect of reforms in the PFM is disclosed;

vi) Approaches in the financial management of incomes and expenditures in the public sector have been explored;

vii) Factors influencing the effectiveness of the PFM reforms have been identified;

viii) Identified challenges in the PFM and formulated opportunities that contribute to the achievement of the PFM's goal.

\section{Conclusions}

The conducted research allowed the formulation of the following conclusions:

i) Due to the specifics of public sector organizations, not all the traditional tools used in financial management in commercial organizations are applicable in the PFM;

ii) The effectiveness of public organizations is difficult to measure and cannot always be measured by quantitative indicators;

iii) Public sector organizations need to be more open to new technologies and innovations, they have to be used wisely.

Financial management in the public sector is a conservative type of professional activity. Not immediately responds to innovations and changes. In addition, the use of new technologies and tools requires a large number of approvals with different units. Ultimately, in order for their application to become possible, financial resources are needed, the rationale of which requires effort and time.

But only using modern technologies and approaches, while not losing the classical professional knowledge and skills required in this field of professional activity, we will be able to answer all the challenges that specialists who are involved in the PFM have to face. 


\section{References}

Baubion C (2013) OECD Risk Management: Strategic Crisis Management. OECD Working Papers on Public Governance, no. 23. Paris: OECD Publishing. Available at: http://dx.doi.org/10.17 87/5k41rbd1lzr7-en.

Berryhill J, Bourgery T, Hanson A (2018) Blockchains Unchained: Blockchain Technology and its Use in the Public Sector. OECD Working Papers on Public Governance, no. 28. Paris: OECD Publishing. Available at: http://dx.doi.org/10.17 $87 / 3 \mathrm{c} 32 \mathrm{c} 429$-en

Curristine T, Lonti Z, Joumard I (2007) Improving public sector efficiency: challenges and opportunities. OECD Journal on Budgeting 7(1). ISSN: 1608-7143, OECD.

Killick T (2005) Policy autonomy and the history of British. Development Policy Review 23(6): 665-681. Available at: https://doi.org/10.1111/j.1467-7679.2005.00307.x.

Guthrie D. (2005) Organizational learning and productivity: state structure and foreign investment in the rise of the chinese corporation. 1(2): 165-195. Available at: https:// doi.org/10.1111/j.17 40-8784.2005.00008.x.

Global Financial Management Leaders Survey (2015) Innovation in Public Financial Management in an Increasingly Complex and Uncertain Global Environment, Grant Thornton. Available at: https://bit.ly/2VVIhzF.

Lawson A (2015) Public Financial Management. GSDRC Professional Development Reading Pack no. 6. Birmingham, UK: GSDRC, University of Birmingham.

Olander S (2007) Stakeholder impact analysis in construction project management. Construction Management and Economics 25(3): 277 - 287.

Order of the Ministry of Finance of Russia (2017) On the Organization of Monitoring the Quality of Financial Management, Implemented by State Administrators of Budget Funds of the Federal Budget, no 62n, 16.12.2017. Available at: www.fm.ru.

PEFA (2016) Framework for Assessing Public Financial Management. Washington DC 20433, USA. Available at: https://pefa.org/content/pefa-framework.

PEFA (2009) Public Financial Management Performance Measurement Framework. Washington DC USA: Secretariat World Bank. Available at: https://bit.ly/2YHLyzC.

Rakner L, Mukubvu L, Ngwira N, Smiddy K, Schneider A (2004) The budget as theatre the formal and informal institutional makings of the budget process in Malawi, 54. Bergen: Chr. Michelsen Institute.

Review of Public Financial Management Reform Literature (2009) Evaluation Report EV698. London: DFID. Available at: https://bit.ly/2YHLyzC.

Ubaldi B (2013) Open Government Data: Towards Empirical Analysis of Open Government Data Initiatives. OECD Working Papers on Public Governance, no. 22. Paris: OECD Publishing. Available at: http://dx.doi.org/10.1787/5k46bj4f03s7-en.

Erasmus PW, Visser C (2002) The Management of Public Finance: A Practical Guide, 983. Cape Town: OUP Southern Africa.

Yu H, Robinson DG (2012) The New Ambiguity of 'Open Government' (February 28, 2012). 59 UCLA L. Rev. Disc. 178(2012). Available at http://dx.doi.org/10.2139/ss rn.2012489. 